\title{
Characteristics of Cardiac Memory in Patients with Implanted Cardioverter Defibrillator: the CAMI study
}

Kazi T. Haq ${ }^{1}$, PhD, Jian $\mathrm{Cao}^{2}$, PhD, and Larisa G. Tereshchenko ${ }^{1}$, MD, PhD

From

${ }^{1}$ Knight Cardiovascular Institute, Oregon Health and Science University, Portland, OR, ${ }^{2}$ Medtronic, Inc, Minneapolis, MN.

Short title: cardiac memory in ICD patients

Correspondence: Larisa Tereshchenko, 3181 SW Sam Jackson Park Rd; UHN62; Portland, OR, 97239. E-mail:tereshch@ohsu.edu. Phone: 503-494-7400; Fax: 503-494-8550.

Total words: 5970 


\begin{abstract}
Objective-The goal of this study was to determine factors associated with cardiac memory (CM) in patients with implantable cardioverter-defibrillators (ICD).

Methods-Patients with structural heart disease (n=20; mean age 72.6 \pm 11.6 y; $80 \%$ male; mean left ventricular ejection fraction (LVEF) 31.7 $\pm 7.6 \%$; history of myocardial infarction (MI) in $75 \%$, ventricular tachycardia (VT) in $85 \%$ ) and preserved atrioventricular (AV) conduction received primary $(80 \%)$ or secondary $(20 \%)$ prevention dual-chamber ICD. Standard 12-lead ECG was recorded in AAI and DDD mode, before and after 7 days of right ventricular (RV) pacing in DDD mode with short AV delay. Direction (azimuth and elevation) and magnitude of spatial QRS, T, and ventricular gradient (SVG) vectors were measured before and after 7 days of RV pacing. CM was quantified as the degree of alignment between $\mathrm{QRS}_{\mathrm{DDD}-7}$ and $\mathrm{T}_{\mathrm{AAI}-7}$ vectors (QRS DDD-7-T $_{\text {AAI-7 }}$ angle). Circular statistics and mixed models with a random slope and intercept were adjusted for days 1-7 change in cardiac activation, LVEF, known risk factors, and use of medications known to affect CM.
\end{abstract}

Results-QRS $\mathrm{DDD}_{\mathrm{D}-7}-\mathrm{T}_{\mathrm{AAI}-7}$ angle strongly correlated (circular $\mathrm{r}=-0.972 ; \mathrm{P}<0.0001$ ) with $\mathrm{T}_{\text {AAI-7 }}-\mathrm{T}_{\mathrm{DDD}-7}$ angle. In the mixed models, history of $\mathrm{MI}\left(-180^{\circ}\left(95 \% \mathrm{CI}-320^{\circ}\right.\right.$ to $\left.\left.-40^{\circ}\right) ; \mathrm{P}=0.011\right)$ and female sex $\left(-162^{\circ}\left(95 \% \mathrm{CI}-268^{\circ}\right.\right.$ to $\left.\left.-55^{\circ}\right) ; \mathrm{P}=0.003\right)$ counteracted $\mathrm{CM}-\mathrm{T}$ azimuth changes $\left(+132^{\circ}\left(95 \% \mathrm{CI}^{\circ} 0^{\circ}-184^{\circ}\right) ; \mathrm{P}<0.0001\right)$. History of VT $\left(+27(95 \% \mathrm{CI} 4-46) \mathrm{mV}^{*} \mathrm{~ms} ; \mathrm{P}=0.007\right)$ amplified CM-T area increase $\left(+15\left(95 \%\right.\right.$ CI 6-24) $\left.\mathrm{mV}^{*} \mathrm{~ms} ; \mathrm{P}<0.0001\right)$.

Conclusions-Existing cardiac remodeling affects CM in response to RV pacing. Women develop less CM than men. Activation memory is another manifestation of CM.

Keywords: cardiac memory; vectorcardiogram. 
Right ventricular (RV) apical pacing can cause pacing-induced cardiomyopathy ${ }^{1,2}$ : nearly every fifth patient develops pacing-induced cardiomyopathy if RV pacing burden $\geq 20 \%{ }^{3,4}$. Biventricular pacing and His bundle pacing ${ }^{5}$ are more physiological, but also more technically challenging pacing approaches. An informed clinical decision regarding the choice of pacing approach should be based on the evaluation of risks and benefits for each patient. Unfortunately, it remains largely unknown which factors (besides pacing burden) are associated with pacinginduced cardiomyopathy.

$\mathrm{RV}$ pacing changes activation pathway and induces complex repolarization phenomenon of cardiac memory $(\mathrm{CM}) .{ }^{6} \mathrm{CM}$ is a form of cardiac remodeling caused by altered myocardial stretch. ${ }^{7}$ Altered ventricular stretch and subsequent local cardiac angiotensin II release but not altered ventricular activation initiates $\mathrm{CM} .{ }^{8}$ The $\mathrm{T}$ wave changes of $\mathrm{CM}$ result from underlying changes in ion channels $\left(I_{\mathrm{to}}, I_{\mathrm{kr}}, I_{\mathrm{Ca}, \mathrm{L}}\right)$ and connexin43 remodeling. ${ }^{7} \mathrm{CM}$ can be fully reversible after return to normal activation pathway. All these facts suggest that the amount of $\mathrm{CM}$ developed in response to RV pacing is likely associated with clinical outcomes. However, while molecular mechanisms of CM have been extensively studied, ${ }^{6}$ its translation into clinical practice has been limited. ${ }^{9}$ Current clinical perception of $\mathrm{CM}$ is restricted by recognition of $\mathrm{T}$ wave inversion that develops after a period of altered ventricular activation once normal ventricular activation is restored, differentiating $\mathrm{CM}$ from ischemic T wave inversion. ${ }^{10}$

Previously, CM was studied in patients undergoing pacemaker implantation. ${ }^{11-14}$ An interaction of RV pacing-induced CM with preexisting cardiac remodeling [e.g. after myocardial infarction (MI) and ventricular tachycardia (VT)] remains incompletely understood. The goal of this study was to determine factors associated with CM in patients receiving implantable 
medRxiv preprint doi: https://doi.org/10.1101/19005181; this version posted November 26, 2019. The copyright holder for this preprint (which was not certified by peer review) is the author/funder, who has granted medRxiv a license to display the preprint in perpetuity.

All rights reserved. No reuse allowed without permission.

cardioverter defibrillators (ICD). We hypothesized that preexisting cardiac remodeling is associated with CM.

\section{Methods}

The MATLAB (MathWorks, Inc, Natick, MA) software code for ECG data analysis is provided at https://physionet.org/physiotools/global electrical heterogeneity/,

\section{https://github.com/Tereshchenkolab/Origin, and}

https://github.com/Tereshchenkolab/cardiacmemory. In order to minimize the possibility of unintentionally sharing information that can be used to re-identify private information, a subset of the data generated for this study are available at the GitHub and can be accessed at https://github.com/Tereshchenkolab/cardiacmemory/QRS_T_DDD2_AAI2.

\section{Study population}

The Cardiac Memory with ICD (CAMI) prospective study was conducted by Medtronic. The study participants were enrolled at the Beth Israel Deaconess Medical Center (BIDMC), and the data analysis was performed at the Oregon Health \& Science University (OHSU). The study was approved by the Institutional Review Boards at the BIDMC and the OHSU. All study participants signed an informed consent before entering the study.

The CAMI study included adults above 18 years of age who have received a Medtronic market released dual-chamber ICD with chronically implanted (for at least 3 months, $\geq 90$ days) Medtronic RV leads with SVC coil and RV ring electrode (Sprint Fidelis, Sprint Quattro Secure 6947, Sprint Quattro 6944, etc.) for approved indications. The RV tip location must be in the RV apex. Patients must have sinus rhythm with 1:1 AV conduction at physiological heart rates at baseline. 
Exclusion criteria were: (1) a history of unstable angina pectoris within the last 3 months unless treated by coronary intervention; (2) inability to tolerate DDD pacing or AAI pacing due to subjective discomfort, heart failure, or other reasons; (3) anti-tachycardia pacing or shock therapy from ICD for spontaneous tachyarrhythmia episodes for the last 3 months; (4) more than $1 \%$ of RV pacing for the last 3 months (confirmed by the ICD device interrogation); (5) NYHA class III-IV congestive heart failure; (6) left ventricular ejection fraction (LVEF) < 20\%; (7) baseline ECG abnormalities (complete left bundle branch block, T wave inversions secondary to left ventricular hypertrophy) precluding expression of CM; (8) inaccessible for follow-up at the study center.

\section{ECG recording and pacing protocol: induction of cardiac memory}

At the baseline study visit, resting supine 12 lead electrocardiogram (ECG) was recorded using a MAC 5000 electrocardiograph (GE Marquette, Milwaukee, WI), in AAI and DDD mode with a short AV delay at a rate $10 \%$ faster than presented sinus rhythm. Then, ICD devices were programmed in the DDD mode with a short (100-120 ms) paced and sensed AV delay and lower rate as clinically indicated.

The second study visit was conducted after seven days of ventricular pacing when ICD devices were interrogated, and the percentage of ventricular pacing data was collected. During the follow-up visit, resting 12-lead ECG was recorded first in DDD mode, and then in AAI mode. The pacing rate during ECG recording on a follow-up visit maintained the same as at the baseline ECG recording.

\section{Measurement of cardiac memory on the body surface vectorcardiogram}

The raw digital 12-lead ECG signal (sampling rate $500 \mathrm{~Hz}$, amplitude resolution $1 \mu \mathrm{V}$ ) was analyzed at OHSU. Kors matrix ${ }^{15}$ was used to transform the 12-lead ECG into orthogonal XYZ 
ECG. All 10-second ECG recordings were reviewed, and all beats were manually labeled (LGT). Ectopic beats, fusion beats, and artifact-distorted beats were excluded from the analysis. Four types of median beats were constructed: AAI mode atrial-paced ventricular-sensed (APVS) beat recorded on the study day one (AAI-1) and day seven (AAI-7), and DDD mode atrial-paced ventricular-paced (APVP) beat recorded on the study day one (DDD-1) and day seven (DDD-7). The heart vector origin point was identified as previously described. ${ }^{16}$ Fiducial points (QRS onset and offset, and T offset) were automatically detected on a vector magnitude. Accuracy of the origin point and fiducial point detection was verified using a visual aid (KTH, LGT). Spatial peak and area QRS, T, and spatial ventricular gradient (SVG) vectors were defined as previously described, ${ }^{17}$ and their direction (azimuth and elevation) and magnitude were measured. The scalar value of SVG was measured by the sum absolute QRST integral (SAI QRST) ${ }^{18,19}$ and QT integral on vector magnitude signal (iVMQT). ${ }^{17}$

$\mathrm{CM}$ was quantified after seven days of ventricular pacing, as the degree of alignment between VP QRS vector $\left(\mathrm{QRS} \mathrm{DDD}_{\mathrm{D}-7}\right)$ and VS T vector $\left(\mathrm{T}_{\mathrm{AAI}-7}\right)$, measured as $\mathrm{QRS}$ DDD-7- $\mathrm{T}_{\mathrm{AAI}-7}$ angle. Changes in ventricular repolarization were assessed as $\mathrm{T}_{\mathrm{AAI}-1-\mathrm{T}_{\mathrm{AAI}-7} \text { and } \mathrm{T}_{\mathrm{DDD}-1}-\mathrm{T}_{\mathrm{DDD}-7} \text {, as }}$ well as $\mathrm{T}_{\mathrm{AAI}-1}-\mathrm{T}_{\mathrm{DDD}-1}$ and $\mathrm{T}_{\mathrm{AAI}-7}-\mathrm{T}_{\mathrm{DDD}-7}$ angles.

The difference in ventricular activation between VS and VP QRS vectors was measured by QRS $_{\text {AAI-7-QRS }}$ DDD-7 angle. To eliminate an error due to possible differences in ECG leads placement between days one and seven, CM angles were measured on the same day recordings. To assess a possible error due to ECG leads placement on two different days, we measured spatial angles $\mathrm{QRS}_{\mathrm{DDD}-1-\mathrm{QRS}} \mathrm{DDD}-7_{\text {and }} \mathrm{QRS}_{\mathrm{AAI}-1-\mathrm{QRS}_{\mathrm{AAI}-7} \text {, and an agreement between angles }}$ $\mathrm{QRS}_{\mathrm{AAI}-7-\mathrm{QRS}} \mathrm{DDD}-7_{\mathrm{D}}$ and $\mathrm{QRS} \mathrm{SAI}_{\mathrm{A}-1-\mathrm{QRS}} \mathrm{SDD}-1_{\mathrm{D}}$ 


\section{Ventricular pacing vector}

On VCG, VP vector was defined as a median VP spike calculated on the 10-sec recording.

\section{Statistical analyses}

The distribution of all variables was evaluated. Normally distributed continuous variables were presented as mean \pm standard deviation (SD). A paired $t$-test was used to compare normally distributed VCG parameters at different pacing modes, at baseline and after seven days of ventricular pacing.

Circular statistics were used to analyze circular variables (spatial angles, azimuth, and elevation). To describe circular variable, mean circular direction and 95\% confidence interval (CI) were reported. Non-uniformity of the circular variable distribution was confirmed by the Rayleigh test and the Kuiper test for all studied circular variables. A paired comparison of circular variables was performed using the Hotelling's paired test. The circular-circular correlation coefficients between two circular variables were calculated by the Fisher \& Lee method. The circular-linear correlation coefficients were calculated by the Fisher, Mardia \& Jupp method. The Watson U-square statistic and the Kuiper statistics were used for two-sample tests for circular variables. To account for multiple testing in correlation analyses, the correlation was considered statistically significant if the P-value was less than 0.001 .

To determine associations of demographic and clinical characteristics with changes in $\mathrm{T}$ and QRS vectors over the course of 7 days, we conducted longitudinal analysis and constructed two sets of mixed models. One set of models was built to predict changes in direction and magnitude of T area vector, separately in the AAI (VS) mode and DDD (VP) mode. Another set of models was built to predict changes in the direction and magnitude of the QRS area vector in DDD (VP) mode. As there was prominent person-to-person variability in QRS and T vector changes, we 
constructed mixed models with a random slope and intercept. The Hausman specification test confirmed the consistency of random effect estimates for all models. We used an unstructured covariance structure. A likelihood ratio test confirmed a better model fit for a random slope, for all models. To test our hypothesis that preexisted remodeling can affect the development of CM, we constructed two models. Model 1 was adjusted for age, sex, and two major causes of preexisted CM: a history of MI and VT. Model 2 was in addition adjusted for other known factors affecting cardiac remodeling: LVEF, history of diabetes, hypertension, use of angiotensin-converting enzyme inhibitors (ACEi) or angiotensin receptor blockers (ARBs), and class III antiarrhythmic (AA) drugs. To adjust for possible unmeasured confounders (e.g. due to differences in ECG leads location in days 1 and 7, or unmeasured disease-related factors), both models 1 and 2 were adjusted for longitudinal change in corresponding QRS variable. Model of T (and SVG) azimuth change was adjusted for QRS azimuth change. Model of T (and SVG) elevation change was adjusted for QRS elevation change. The model of T area change was adjusted for the QRS area change. In addition, we tested the hypothesis that T azimuth (and T area) change during abnormal activation (in DDD mode) is associated with QRS azimuth (and QRS area) change, adjusting for the same confounders in models 1 and 2. In mixed models, a P value less than 0.05 was considered significant.

STATA MP 16 (StataCorp LP, College Station, TX) and Oriana-Circular Statistics 4 (Kovach Computing Services, Pentraeth, Wales, UK) were used for statistical analyses. 


\section{Results}

\section{Study population}

The clinical characteristics of the study participants are shown in Table 1. Most of the study participants were men with ischemic cardiomyopathy and ICD implanted for primary prevention of sudden cardiac death (SCD). Of note, $85 \%$ had a history of VT, and nearly half had a sustained VT. The vast majority of participants were on beta-blockers and ACEi/ARBs, and onethird of participants received class III antiarrhythmic medications (sotalol or amiodarone). During the seven study days, all study participants experienced constant RV pacing: the average percentage of RV pacing was $99.73 \pm 0.23 \%$ (range $99.3-100 \%$ ).

\section{Development of cardiac memory}

Mean CM angle $(\mu)$ was $67.5^{\circ}\left(95 \%\right.$ CI $\left.47.6^{\circ}-87.4^{\circ}\right)$; median $58.2^{\circ}$; length of mean vector $r$ was 0.727 ; concentration $(\kappa)$ was 2.2 ; circular variance 0.27 ; circular $\operatorname{SD} 45.7^{\circ}$.

In paired comparison, there were no differences in RR' interval across all four recordings (Table 2). At baseline, in APVS AAI-1 beat, the QRS vector pointed to the left and slightly backward, whereas the T vector pointed straight forward (indicating preceding remodeling), resulting in a wide baseline QRS-T angle.

Ventricular pacing in day one (APVP DDD-1 beat) caused QT prolongation, QRS widening, rotation of QRS vector further backward and up, rotation of T vector down and leftward, and further widening of QRS-T angle. Notably, the direction of Wilson's SVG vector did not change, whereas its magnitude slightly increased. Magnitudes of QRS and T vectors and areas also increased (Table 2). 
After seven days of VP and return to normal activation (APVS AAI-7 beat), the QRS vector returned to the same direction as in APVS AAI-1 beat. QT and QRS intervals, QRS-T angle, and SVG magnitude in AAI-7 did not differ from AAI-1. As expected, CM on APVS beat manifested by prominent T vector magnitude enlargement, increased SVG and SAI QRST, and dramatic changes in $\mathrm{T}$ vector direction (turned sharply to the right and upward), and SVG vector direction (turned upward and backward).

On the $7^{\text {th }}$ day, we observed very similar differences between APVS and APVP beats (AAI-7 vs. DDD-7), as on the first study day. Neither magnitude nor direction of Wilson's SVG differed between APVS and APVP beats.

Comparison of APVP DDD-1 and DDD-7 beats revealed no differences in direction and magnitude of the QRS vector, the direction of the T vector, and the QRS-T angle. However, the direction of the SVG vector changed dramatically (turned upward and backward), and magnitudes of T, SVG, and SAI QRST significantly decreased. The development of CM is shown in Figure 1.

\section{Baseline repolarization characteristics associated with cardiac memory}

CM angle perfectly $(r=-0.972)$ correlated with $\mathrm{T}_{\mathrm{AAI}-7}-\mathrm{T}_{\mathrm{DDD}-7}$ angle that reflects difference in repolarization in two different activation patterns after development of CM (Figure 2). Correlations between CM $\left(\mathrm{QRS}_{\mathrm{DDD}-7}-\mathrm{T}_{\mathrm{AAI}-7}\right)$ angle and $\mathrm{T}_{\mathrm{AAI}-7}-\mathrm{T}_{\mathrm{AAI}-7}(\mathrm{r}=-0.198), \mathrm{T}_{\mathrm{DDD}-1}-\mathrm{T}_{\mathrm{DDD}-7}$

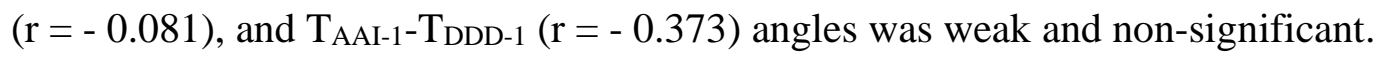

$\mathrm{T}_{\mathrm{AAI}-1}-\mathrm{T}_{\mathrm{AAI}-7}$ angle negatively correlated with baseline $\mathrm{T}_{\mathrm{AAI}-1}$ peak magnitude $(\mathrm{r}=-0.738$; $\mathrm{P}<0.0001)$ and $\mathrm{T}_{\text {AAI-1 }}$ area $(\mathrm{r}=-0.720 ; \mathrm{P}<0.0001)$, and positively correlated with $\mathrm{T}_{\mathrm{AAI}-1}$ azimuth (Figure 2), both $\mathrm{T}_{\text {AAI-1 }}$ peak azimuth $(\mathrm{r}=0.623 ; \mathrm{P}<0.0001)$ and $\mathrm{T}_{\text {AAI-1 }}$ area azimuth $(\mathrm{r}$ 


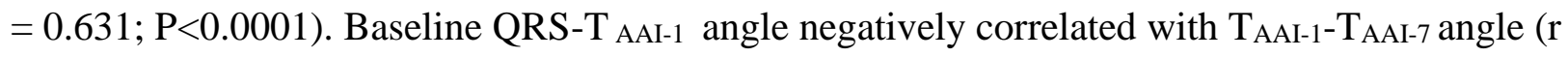
$=-0.692 ; \mathrm{P}<0.0001 ;$ Figure 2).

\section{Baseline characteristics associated with ventricular activation pattern during $R V$ pacing}

The difference in ventricular activation between VS and VP QRS vectors as measured by

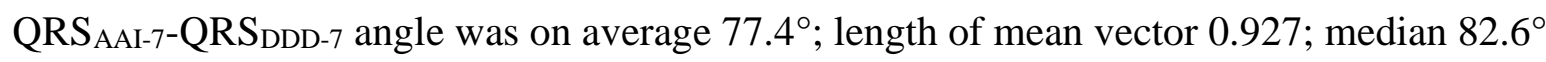
$\left(95 \% \mathrm{CI} 67.7^{\circ}-87.2^{\circ}\right)$. In the paired analysis, there was no difference between $\mathrm{QRS}_{\mathrm{AAI}-7^{-}}$ $\mathrm{QRS}_{\mathrm{DDD}-7}$ and $\mathrm{QRS}_{\mathrm{AAI}-1-\mathrm{QRS}} \mathrm{DDD-1}$ angles. A possible error due to variations in ECG electrodes placement was below 10 degrees. Mean $\mathrm{QRS}_{\mathrm{AAI}-1-\mathrm{QRS}} \mathrm{AAI-7}$ angle was $7.5^{\circ}$; length of mean vector 0.997; median 6.5 $\left(95 \%\right.$ CI 5.5 $\left.-9.5^{\circ}\right)$. Mean QRSDDD-1-QRS $_{\text {DDD-7 }}$ angle was $9.6^{\circ}$; length of mean vector 0.976 ; median $5.0\left(95 \% \mathrm{CI} 4.1^{\circ}-15.1^{\circ}\right)$.

We observed a significant correlation between baseline APVP (DDD-1) repolarization characteristics and differences in ventricular activation in AAI and DDD mode after CM has been developed, as measured by $\mathrm{QRS}_{\mathrm{AAI}-7-\mathrm{QRS}} \mathrm{DDD}_{\mathrm{D}-7}$ angle. Baseline APVP $\mathrm{T}_{\mathrm{DDD}-1}$ azimuth correlated with $\mathrm{QRS}_{\mathrm{AAI}-7-\mathrm{QRS}} \mathrm{DDD-7}_{\text {angle }}(\mathrm{r}=0.604$; $\mathrm{P}<0.001$; Figure 3$)$, but not $\mathrm{QRS}_{\mathrm{AAI}-1 \text { - }}$ $\mathrm{QRS}_{\mathrm{DDD}-1}$ angle $(\mathrm{r}=0.355 ; \mathrm{NS})$. Baseline APVP QT $\mathrm{DDD}_{-1}$ interval was moderately strongly correlated with APVP QRS of APVS QT $\mathrm{AAI}_{-1}$ interval with APVP QRS $\mathrm{DDD}-7$ azimuth was weak $(\mathrm{r}=0.436 ; \mathrm{P}<0.05)$. Baseline APVS $\mathrm{T}_{\mathrm{AAI}-1}$ vector magnitude $(\mathrm{r}=0.653)$ and $\mathrm{T}_{\mathrm{AAI}-1}$ area $(\mathrm{r}=0.601)$ positively correlated with QRS DDD-7 vector elevation on the $7^{\text {th }}$ day during ventricular pacing (Figure 3), but not in a normal ventricular conduction $\left(\mathrm{QRS}_{\mathrm{AAI}-7}\right.$ vector elevation: $\mathrm{r}=0.261$ for $\mathrm{T}_{\mathrm{AAI}-1}$ vector magnitude and $\mathrm{r}=0.333$ for $\mathrm{T}_{\mathrm{AAI}-1}$ area). 
medRxiv preprint doi: https://doi.org/10.1101/19005181; this version posted November 26, 2019. The copyright holder for this preprint (which was not certified by peer review) is the author/funder, who has granted medRxiv a license to display the preprint in perpetuity.

All rights reserved. No reuse allowed without permission.

\section{The direction of Ventricular Pacing vector}

VP vector was directed upward and rightward, consistently with implanted RV lead. In the paired analysis, there was no difference in VP vector azimuth recorded on day one versus day 7

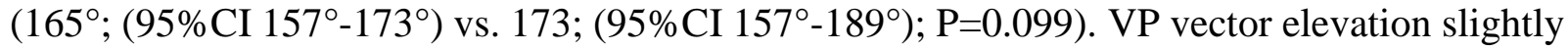
decreased by $10^{\circ}$ one week after RV lead implantation: $\mathrm{V}_{\text {DDD-1 }}$ elevation $110^{\circ}$; $\left(95 \% \mathrm{CI} 102^{\circ}\right.$ $\left.117^{\circ}\right)$ vs. $\mathrm{V}_{\text {DDD-7 }}$ elevation $100^{\circ}\left(95 \% \mathrm{CI}^{\circ} 1^{\circ}-110^{\circ}\right) ; \mathrm{P}=0.006$. There were no meaningful correlations of VP vector direction with cardiac activation or repolarization metrics.

\section{Clinical characteristics associated with cardiac memory}

We observed prominent person-to-person variability in changes of T and SVG vectors that manifest CM (Figure 4). Mixed models analyses results showed that in AAI mode, T azimuth displayed the most dramatic changes from day 1 to day 7 (Table 3). History of MI and female sex was associated with the significant opposite effect on T azimuth, counteracting the development of CM. Change in T elevation was associated only with a change in QRS elevation, but not any clinical or demographic characteristics. History of MI, history of VT, and history of class III antiarrhythmics use was associated with T magnitude changes (Table 3). In DDD mode, the history of VT was associated with changes in SVG azimuth during seven days of follow-up. History of MI, VT, and female sex were associated with changes in SVG elevation, reducing the degree of CM manifestation (Table 3). Similarly, female sex and VT history were associated with T magnitude changes in DDD mode, offsetting the development of CM.

In an adjusted mixed model analysis, we detected changes in ventricular activation as a manifestation of CM. In DDD mode, we observed significant changes in QRS azimuth and area, from day 1 to day 7 (Table 4). Female sex and history of MI were associated with a reduction of QRS azimuth changes, whereas diabetes and LVEF worsening were associated with greater QRS 
azimuth changes. Similar associations were observed for the QRS area. In AAI mode, there were no statistically significant changes in QRS vector direction and magnitude from day 1 to day 7.

\section{Discussion}

In this prospective study of CM in ICD patients, we observed several novel findings. First, we showed that existing cardiac remodeling due to MI and VT significantly affects the degree of $\mathrm{CM}$ in response to RV pacing. Secondly, we, for the first time, demonstrated sex differences in CM development. After adjustment for the type of cardiomyopathy, degree of LV dysfunction, use of medications, and major cardiovascular risk factors (hypertension and diabetes), women developed less CM as compared to men. Thirdly, we noticed that in participants with preceded cardiac remodeling, the $\mathrm{CM}$ is associated with significant changes in cardiac activation. While repolarization memory "remembers" abnormal activation after baseline activation has been restored, activation memory "remembers" normal baseline activation during abnormal (VP) activation, resulting in a smaller angle between QRS vectors of normal (baseline) and abnormal (VP) activation. Further studies of repolarization and activation memory are needed to understand the mechanisms and clinical significance of CM.

\section{Cardiac remodeling is associated with the degree of repolarization memory}

We observed that the more abnormal baseline repolarization was, the less repolarization memory had been developed in response to ventricular pacing. The wider the baseline spatial QRS-T angle was, the less repolarization memory was developed. The larger baseline $\mathrm{T}$ area was, the less repolarization memory was developed. Similarly, the more abnormal was the direction of the baseline $\mathrm{T}$ vector, the less repolarization memory was developed. The abnormal (rightward-forward) direction of T vector, large magnitude of T, and wide QRS-T angle are well- 
known signs of earlier cardiac memory or cardiac remodeling. A more negative T vector azimuth in CM patients with DDD RV pacing ${ }^{20}$ is consistent with our finding of less repolarization memory with more negative $\mathrm{T}$ vector azimuth (Figure 2). Accordingly, in the mixed model analyses adjusted for a change in cardiac activation between days 1 and 7, LV systolic function, known risk factors, and use of medications known to affect the development of cardiac memory, history of MI and VT strongly counteracted repolarization changes. History of MI and VT nearly completely canceled manifestation of CM, both in AAI and DDD modes. Thus, the robust development of typical CM in response to RV pacing suggests an absence or a minimal degree of preexisted cardiac remodeling. In contrast, weak repolarization response to RV pacing implies that repolarization ion channels in ventricular cardiomyocytes had been already remodeled, as shown in many in vitro studies, 7,21,22 and display a saturation of response. Our finding is consistent with CM studies in HF patients undergoing bi-ventricular pacing. ${ }^{12,13}$

\section{Women develop less cardiac memory than men}

Previous studies using animal models ${ }^{22-24}$ or human subjects, ${ }^{6,9,11}$ did not investigate sex differences in CM. Interestingly, in our study, sex was strongly associated with the degree of CM manifestation. In fully adjusted mixed models, female sex was strongly and independently associated with a significantly smaller amount of CM, suggesting that women developed less dyssynchrony in response to RV pacing, as compared to men. Female sex nearly completely canceled manifestation of CM, both in AAI and DDD modes (Table 3). The finding of sex differences in $\mathrm{CM}$ is novel and has an important clinical significance. It is well known that women benefit from cardiac resynchronization therapy (CRT) more than men. ${ }^{25}$ We speculate that sex differences in CM contribute to sex differences in CRT response. 


\section{“Activation memory" is another manifestation of cardiac memory}

A large number of previous studies described CM as a repolarization phenotype. ${ }^{6,9,11,21,24,26}$ In this study, we, for the first time described the manifestation of activation memory. In addition to repolarization memory, which manifests by the wide angle between T vectors in AAI and DDD modes on the $7^{\text {th }}$ day, activation memory is revealed by the narrow angle between QRS vectors in AAI and DDD modes on the $7^{\text {th }}$ day. Repolarization memory manifests by $\mathrm{T}_{\mathrm{AAI}-7}$ vector aligning with abnormal activation vector; repolarization "remembers" abnormal activation. In turn, activation memory manifests during continued abnormal activation, by abnormal activation vector aligning with normal activation vector. Activation memory is likely a compensatory mechanism attempting to minimize dyssynchrony developing in response to sustained abnormal activation. Activation and repolarization are two phases of the repeated cycle, following one after another. Development of repolarization memory affects refractoriness in ventricles, which, in turn, affects the way how ventricles activate. Further studies of activation memory mechanisms and its clinical significance are needed.

\section{Spatial ventricular gradient reflects cardiac memory}

Our results one more time ${ }^{27}$ confirmed Wilson's ventricular gradient ${ }^{28}$ concept, suggesting that the SVG is largely independent of the ventricular activation sequence (no difference between $\mathrm{SVG}_{\mathrm{AAI}-7}$ and $\left.\mathrm{SVG}_{\mathrm{DDD}-7}\right) .{ }^{29,30} \mathrm{SVG}$ is determined by the heterogeneity in the whole area under the action potential across the heart, rather than by heterogeneity in the action potential duration alone. ${ }^{29-31} \mathrm{SVG}$ vector tracked the development of CM better than the T vector (Table 2), especially in DDD mode. Thus, change in SVG direction can be used to assess CM in persistently abnormal activation (during continuous ventricular pacing, bundle branch block). 


\section{Limitations}

The study size was small. Validation of the study findings in a larger study is required.

\section{Funding Sources:}

This research was supported in part by the National Institute of Health HL118277 (LGT). The CAMI study was sponsored by Medtronic, Inc.

\section{Disclosures:}

The CAMI study was sponsored by Medtronic, Inc. JC is an employee of Medtronic, Inc. The sponsor had no role in the design, execution, analyses, and interpretation of the data and results of this study. 


\section{References}

1. Tse HF, Lau CP. Long-term effect of right ventricular pacing on myocardial perfusion and function. J Am Coll Cardiol 1997;29:744-749.

2. Sweeney MO, Hellkamp AS, Ellenbogen KA, et al. Adverse effect of ventricular pacing on heart failure and atrial fibrillation among patients with normal baseline QRS duration in a clinical trial of pacemaker therapy for sinus node dysfunction. Circulation 2003;107:29322937.

3. Khurshid S, Epstein AE, Verdino RJ, et al. Incidence and predictors of right ventricular pacing-induced cardiomyopathy. Heart Rhythm 2014;11:1619-1625.

4. Kiehl EL, Makki T, Kumar R, et al. Incidence and predictors of right ventricular pacinginduced cardiomyopathy in patients with complete atrioventricular block and preserved left ventricular systolic function. Heart Rhythm 2016;13:2272-2278.

5. Sharma PS, Vijayaraman P, Ellenbogen KA. Permanent His bundle pacing: shaping the future of physiological ventricular pacing. Nat Rev Cardiol 2019.

6. Rosen MR, Bergfeldt L. Cardiac memory: The slippery slope twixt normalcy and pathology. Trends in cardiovascular medicine 2015;25:687-696.

7. Ozgen N, Rosen MR. Cardiac memory: a work in progress. Heart Rhythm 2009;6:564570.

8. Sosunov EA, Anyukhovsky EP, Rosen MR. Altered ventricular stretch contributes to initiation of cardiac memory. Heart Rhythm 2008;5:106-113.

9. Shvilkin A, Huang HD, Josephson ME. Cardiac memory: diagnostic tool in the making. Circ Arrhythm Electrophysiol 2015;8:475-482. 
10. Waks JW, Steinhaus DA, Shvilkin A, Kramer DB. Post-pacemaker T-wave Inversions: Cardiac Memory. Am J Med 2016;129:170-172.

11. Shvilkin A, Bojovic B, Vajdic B, Gussak I, Zimetbaum P, Josephson ME. Vectorcardiographic determinants of cardiac memory during normal ventricular activation and continuous ventricular pacing. Heart Rhythm 2009;6:943-948.

12. Wecke L, van Deursen CJ, Bergfeldt L, Prinzen FW. Repolarization changes in patients with heart failure receiving cardiac resynchronization therapy-signs of cardiac memory. $\mathrm{J}$ Electrocardiol 2011;44:590-598.

13. Perrotta L, Ricciardi G, Pieragnoli P, et al. Cardiac memory in cardiac resynchronization therapy: A vectorcardiographic comparison of biventricular and left ventricular pacing. J Electrocardiol 2015;48:571-577.

14. Padeletti L, Fantappie C, Perrotta L, et al. Cardiac memory in humans: vectocardiographic quantification in cardiac resynchronization therapy. Clinical research in cardiology : official journal of the German Cardiac Society 2011;100:51-56.

15. Kors JA, van HG, Sittig AC, van Bemmel JH. Reconstruction of the Frank vectorcardiogram from standard electrocardiographic leads: diagnostic comparison of different methods. EurHeart J 1990;11:1083-1092.

16. Perez-Alday EA, Li-Pershing Y, Bender A, et al. Importance of the heart vector origin point definition for an ECG analysis: The Atherosclerosis Risk in Communities (ARIC) study. Comput Biol Med 2019;104:127-138.

17. Thomas JA, E AP-A, Junell A, et al. Vectorcardiogram in athletes: The Sun Valley Ski Study. Ann Noninvasive Electrocardiol 2019;24:e12614. 
18. Sur S, Han L, Tereshchenko LG. Comparison of sum absolute QRST integral, and temporal variability in depolarization and repolarization, measured by dynamic vectorcardiography approach, in healthy men and women. PLoS One 2013;8:e57175.

19. Tereshchenko LG, Cheng A, Fetics BJ, et al. Ventricular arrhythmia is predicted by sum absolute QRST integralbut not by QRS width. J Electrocardiol 2010;43:548-552.

20. Wecke L, Rubulis A, Lundahl G, Rosen MR, Bergfeldt L. Right ventricular pacinginduced electrophysiological remodeling in the human heart and its relationship to cardiac memory. Heart Rhythm 2007;4:1477-1486.

21. Yu H, McKinnon D, Dixon JE, et al. Transient outward current, Ito1, is altered in cardiac memory. Circulation 1999;99:1898-1905.

22. Obreztchikova $\mathrm{MN}$, Patberg $\mathrm{KW}$, Plotnikov AN, et al. $\mathrm{I}(\mathrm{Kr})$ contributes to the altered ventricular repolarization that determines long-term cardiac memory. CardiovascRes 2006;71:88-96.

23. Shvilkin A, Danilo P, Jr., Wang J, et al. Evolution and resolution of long-term cardiac memory. Circulation 1998;97:1810-1817.

24. Costard-Jackle A, Goetsch B, Antz M, Franz MR. Slow and long-lasting modulation of myocardial repolarization produced by ectopic activation in isolated rabbit hearts. Evidence for cardiac "memory". Circulation 1989;80:1412-1420.

25. Gillis AM. Atrial Fibrillation and Ventricular Arrhythmias: Sex Differences in Electrophysiology, Epidemiology, Clinical Presentation, and Clinical Outcomes. Circulation 2017;135:593-608. 
26. Coronel R, Opthof $\mathrm{T}$, Plotnikov $\mathrm{AN}$, et al. Long-term cardiac memory in canine heart is associated with the evolution of a transmural repolarization gradient. CardiovascRes 2007;74:416-425.

27. Tereshchenko LG, Ghanem RN, Abeyratne A, Swerdlow CD. Intracardiac QT integral on far-field ICD electrogram predicts sustained ventricular tachyarrhythmias in ICD patients. Heart Rhythm 2011;8:1889-1894.

28. Wilson FN, Macleod AG, Barker PS. The distribution of the action currents produced by heart muscle and other excitable tissues immersed in extensive conducting media. The Journal of general physiology 1933;16:423-456.

29. Geselowitz DB. The ventricular gradient revisited: relation to the area under the action potential. IEEE Trans BiomedEng 1983;30:76-77.

30. Plonsey R. A contemporary view of the ventricular gradient of Wilson. J Electrocardiol $1979 ; 12: 337-341$.

31. Waks JW, Tereshchenko LG. Global electrical heterogeneity: A review of the spatial ventricular gradient. J Electrocardiol 2016;49:824-830. 


\section{Figure legends}

Figure 1. A representative example of QRS and T loops with corresponding peak vectors in median beats recorded at baseline (AAI-1; green) and after the development of CM (AAI-7; black, and DDD-7; red). Median pacing spike vector is shown as a purple arrow.

Figure 2. Repolarization memory. (A) Scatterplot of $\mathrm{QRS}_{\mathrm{DDD}-7}-\mathrm{T}_{\mathrm{AAI}-7}$ angle (y-axis) against $\mathrm{T}_{\mathrm{DDD}-7}-\mathrm{T}_{\mathrm{AAI}-7}$ angle (x-axis). Scatterplot of $\mathrm{T}_{\mathrm{DDD}-7}-\mathrm{T}_{\mathrm{AAI}-7}$ angle (y-axis) against $(\mathbf{B}) \mathrm{T}_{\mathrm{AAI}-1}$ area (x-axis), (C) T $\mathrm{TAI}_{\mathrm{AA}-1}$ azimuth (x-axis), and (D) QRS-T $\mathrm{AAI-1}$ angle. A linear best fit line is shown.

Figure 3. Activation memory. (A) Scatterplot of $\mathrm{QRS}_{\mathrm{AAI}-7}-\mathrm{QRS}_{\mathrm{DDD}-7}$ angle (y-axis) against

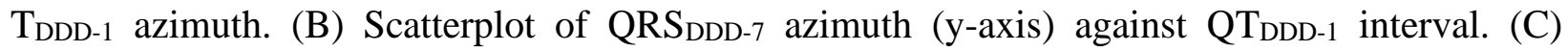
Scatterplot of $\mathrm{QRS}_{\mathrm{DDD}-7}$ elevation against $\mathrm{T}_{\mathrm{AAI}-1}$ magnitude. A linear best fit is shown.

Figure 4. A manifestation of cardiac memory in AAI and DDD mode. Time-series line plots show the change in repolarization from day 1 to day 7 , for every study participant. Top panels show the change in T azimuth, T elevation, and area $\mathrm{T}$ in AAI mode. The bottom panel shows the change in SVG azimuth, SVG elevation, and area T in DDD mode. 
Table 1. Clinical characteristics of study participants

\begin{tabular}{ll}
\hline Characteristic & All participants (n=20) \\
\hline Age(SD), y & $72.6(11.1)$ \\
Female, n(\%) & $4(20)$ \\
Percentage of ventricular pacing during 7 days in the study(SD) & $99.7(0.2)$ \\
LVEF(SD), \% & $31.7(7.6)$ \\
Primary prevention ICD, n(\%) & $16(80)$ \\
NYHA class II-III, n(\%) & $10(50)$ \\
History of coronary heart disease, n(\%) & $17(85)$ \\
History of myocardial infarction, n(\%) & $15(75)$ \\
Location of infarction: anterior, n(\% of patients with MI Hx) & $4(27)$ \\
$\quad$ Infero-posterior, n(\% of patients with MI Hx) & $9(60)$ \\
History of revascularization, n(\%) & $2(13)$ \\
Hypertension, n(\%) & $13(65)$ \\
Diabetes, n(\%) & $10(50)$ \\
Atrial fibrillation, n(\%) & $7(35)$ \\
History of ventricular tachycardia, n(\%) & $9(45)$ \\
History of sustained ventricular tachycardia, n(\%) & $17(85)$ \\
Class III antiarrhythmic medications, n(\%) & $8(40)$ \\
Beta-blockers, n(\%) & $6(30)$ \\
Digoxin, n(\%) & $19(95)$ \\
Calcium channel blocker, n(\%) & $4(20)$ \\
Diuretics, n(\%) & $2(10)$ \\
ACE inhibitors / angiotensin receptor blockers, n(\%) & $9(45 \%)$ \\
\hline ACE $(\%)$ & $16(80)$ \\
\hline
\end{tabular}

$\mathrm{ACE}=$ angiotensin converting enzyme 
Table 2. Cardiac memory development

\begin{tabular}{|c|c|c|c|c|c|c|c|c|}
\hline ECG and VCG parameters & AAI-1 & DDD-1 & AAI-7 & DDD-7 & $\mathrm{P}_{\text {AAI1-AAI7 }}$ & $\mathrm{P}_{\mathrm{DDD1} 1 \mathrm{DDD} 7}$ & $\mathrm{P}_{\mathrm{AAI1-DDD1}}$ & $\mathrm{P}_{\text {AAI7-DDD7 }}$ \\
\hline RR interval(SD), ms & $830(125)$ & $825(119)$ & $833(122)$ & $825(118)$ & 0.406 & 0.926 & 0.456 & 0.203 \\
\hline QT interval(SD), ms & $407(45)$ & $465(53)$ & $411(53)$ & $456(43)$ & 0.480 & 0.204 & $<0.0001$ & $<0.0001$ \\
\hline QRS duration(SD), ms & 111(17) & $162(23)$ & $113(15)$ & $167(20)$ & 0.492 & 0.263 & $<0.0001$ & $<0.0001$ \\
\hline Spatial QRS area(SD), $\mathrm{mV}^{*} \mathrm{~ms}$ & $50(27)$ & $120(41)$ & $50(24)$ & $120(36)$ & 0.611 & 0.902 & $<0.0001$ & $<0.0001$ \\
\hline Spatial peak QRS vector magnitude(SD), $\mathrm{mV}$ & $1.31(0.41)$ & $1.45(0.43)$ & $1.31(0.35)$ & $1.42(0.40)$ & 0.907 & 0.909 & 0.046 & 0.187 \\
\hline Spatial area QRS vector azimuth $(95 \% \mathrm{CI}){ }^{\circ}$ & $37(25-49)$ & $99(90-108)$ & $37(24-49)$ & 104(96-111) & 0.198 & 0.384 & $<0.0001$ & $<0.0001$ \\
\hline Spatial peak QRS vector azimuth $(95 \% \mathrm{CI}){ }^{\circ}$ & $32(18-46)$ & $98(89-106)$ & $31(17-44)$ & $102(95-110)$ & 0.964 & 0.326 & $<0.0001$ & $<0.0001$ \\
\hline Spatial area QRS vector elevation(95\%CI), ${ }^{\circ}$ & $82(74-90)$ & $122(117-128)$ & $78(70-86)$ & $124(117-130)$ & 0.058 & 0.202 & $<0.0001$ & $<0.0001$ \\
\hline Spatial peak QRS vector elevation $(95 \% \mathrm{CI}){ }^{\circ}$ & $81(73-88)$ & $121(116-126)$ & $78(71-86)$ & $124(118-130)$ & 0.126 & 0.160 & $<0.0001$ & $<0.0001$ \\
\hline Spatial $\mathrm{T}$ area(SD), $\mathrm{mV} * \mathrm{~ms}$ & $39(29)$ & $142(55)$ & $54(25)$ & $94(35)$ & 0.007 & $<0.0001$ & $<0.0001$ & 0.0002 \\
\hline Spatial peak $\mathrm{T}$ vector magnitude(SD), $\mathrm{mV}$ & $0.28(0.17)$ & $0.91(0.29)$ & $0.38(0.14)$ & $0.64(0.17)$ & 0.003 & $<0.0001$ & $<0.0001$ & 0.0001 \\
\hline Spatial area T vector azimuth $(95 \% \mathrm{CI}),{ }^{\circ}$ & $-102(-117$ to -88$)$ & $-65(-73$ to -57$)$ & $166(156$ to -175$)$ & $-71(-79$ to -62$)$ & $<0.0001$ & 0.123 & $<0.0001$ & $<0.0001$ \\
\hline Spatial peak T vector azimuth $(95 \% \mathrm{CI}){ }^{\circ}$ & $-92(-109$ to -74$)$ & $-63(-71$ to -54$)$ & $161(140-182)$ & $-67(-77$ to -58$)$ & $<0.0001$ & 0.168 & $<0.0001$ & $<0.0001$ \\
\hline Spatial area $\mathrm{T}$ vector elevation $(95 \% \mathrm{CI}){ }^{\circ}$ & $87(80-95)$ & $56(50-62)$ & $118(110-126)$ & $55(48-61)$ & $<0.0001$ & 0.423 & $<0.0001$ & $<0.0001$ \\
\hline Wilson's (area) SVG (SD), mV*ms & $36(22)$ & $45(31)$ & $44(17)$ & $42(14)$ & 0.212 & 0.615 & 0.027 & 0.209 \\
\hline Spatial peak SVG vector magnitude(SD), $\mathrm{mV}$ & $0.28(0.17)$ & $0.91(0.29)$ & $0.38(0.14)$ & $0.64(0.17)$ & 0.003 & $<0.0001$ & $<0.0001$ & 0.0001 \\
\hline Spatial area SVG vector azimuth $(95 \% \mathrm{CI}){ }^{\circ}$ & $7(-15$ to 29$)$ & $1(-18$ to 20$)$ & $91(78-105)$ & $76(52-101)$ & $<0.0001$ & $<0.0001$ & 0.308 & 0.118 \\
\hline Spatial peak SVG vector azimuth $(95 \% \mathrm{CI}),{ }^{\circ}$ & $27(12-43)$ & $67(52-81)$ & $44(30-57)$ & $91(82-101)$ & 0.001 & 0.003 & $<0.0001$ & $<0.0001$ \\
\hline Spatial area SVG vector elevation(95\%CI) ${ }^{\circ}$ & $69(60-78)$ & $70(60-81)$ & 107(96-118) & $108(95-121)$ & $<0.0001$ & $<0.0001$ & 0.510 & 0.910 \\
\hline Spatial peak SVG vector elevation $(95 \% \mathrm{CI}){ }^{\circ}$ & $78(70-85)$ & $112(106-119)$ & $84(78-91)$ & $122(114-130)$ & 0.001 & 0.016 & $<0.0001$ & $<0.0001$ \\
\hline SAI QRST(SD), mV*ms & $157(74)$ & $415(141)$ & $181(61)$ & $329(90)$ & 0.006 & 0.0001 & $<0.0001$ & $<0.0001$ \\
\hline Vector magnitude QT integral(SD), mV*ms & $106(50)$ & $268(91)$ & $118(42)$ & $219(66)$ & 0.022 & 0.0001 & $<0.0001$ & 0.0001 \\
\hline Spatial area QRS-T angle $(95 \% \mathrm{CI}){ }^{\circ}$ & $136(121-151)$ & $164(159-169)$ & $131(120-141)$ & $168(165-171)$ & 0.107 & 0.218 & 0.0005 & $<0.0001$ \\
\hline Spatial peak QRS-T angle $(95 \% \mathrm{CI}){ }^{\circ}$ & $115(94-135)$ & $161(156-166)$ & $123(114-134)$ & $166(162-169)$ & 0.435 & 0.025 & 0.0001 & $<0.0001$ \\
\hline
\end{tabular}


Table 3. Demographic and clinical characteristics associated with cardiac memory

\begin{tabular}{|c|c|c|c|c|c|c|c|c|c|c|c|c|c|}
\hline & \multirow[b]{2}{*}{ Characteristic } & \multicolumn{6}{|c|}{ Outcome variables in AAI mode } & \multicolumn{6}{|c|}{ Outcome variables in DDD mode } \\
\hline & & $\begin{array}{l}\text { Area T azimuth } \\
(95 \% \mathrm{CI}){ }^{\circ}\end{array}$ & $P$ & $\begin{array}{l}\text { Area T elevation } \\
(95 \% \mathrm{CI}){ }^{\circ}\end{array}$ & $P$ & $\begin{array}{l}\mathrm{T} \text { area }(95 \% \mathrm{CI}), \\
\mathrm{mV}^{*} \mathrm{~ms}\end{array}$ & $\mathrm{P}$ & $\begin{array}{l}\text { Area SVG azimuth } \\
(95 \% \mathrm{CI}){ }^{\circ}\end{array}$ & $\mathrm{P}$ & $\begin{array}{l}\text { Area SVG elevation } \\
(95 \% \mathrm{CI}),{ }^{\circ}\end{array}$ & $\mathrm{P}$ & $\begin{array}{l}\mathrm{T} \text { area }(95 \% \mathrm{CI}), \\
\mathrm{mV} * \mathrm{~ms}\end{array}$ & $\mathrm{P}$ \\
\hline M 1 & Cardiac Memory & $+132(81-182)$ & $<0.0001$ & $+29(20-37)$ & $<0.0001$ & $+15(7-24)$ & 0.001 & $+45(21-69)$ & $<0.0001$ & $+37(26-50)$ & $<0.0001$ & $-48(-60$ to -35$)$ & $<0.0001$ \\
\hline M 2 & $\begin{array}{l}\text { measured by outcome } \\
\text { (change Day 1- Day } 7 \text { ) }\end{array}$ & $+132(80-184)$ & $<0.0001$ & $+29(21-38)$ & $<0.0001$ & $+15(6-24)$ & $<0.0001$ & $+45(23-69)$ & $<0.0001$ & $+37(26-48)$ & $<0.0001$ & $-48(-60$ to -36$)$ & $<0.0001$ \\
\hline M 1 & \multirow{2}{*}{$\begin{array}{c}\text { Corresponding QRS } \\
\text { variable* }\end{array}$} & $-0.4(-1.3$ to 0.4$)$ & 0.297 & $-0.5(-0.9$ to -0.1$)$ & 0.008 & $+0.5(0.1-0.8)$ & 0.005 & $-0.04(-0.8$ to 0.7$)$ & 0.916 & $+0.6(-0.1$ to 1.2$)$ & 0.115 & $+0.9(0.6-1.1)$ & $<0.0001$ \\
\hline M 2 & & $-0.4(-1.4$ to 0.7$)$ & 0.501 & $-0.3(-0.7$ to 0.06$)$ & 0.104 & $+0.5(0.3-0.8)$ & $<0.0001$ & $-0.2(-1.1$ to 0.6$)$ & 0.575 & $+0.5(-0.2$ to 1.3$)$ & 0.150 & $+0.7(0.5-1.0)$ & $<0.0001$ \\
\hline M 1 & \multirow{2}{*}{ Age, per 1 y } & $+3(-0.8$ to 6$)$ & 0.132 & $+0.01(-0.5$ to 0.5$)$ & 0.967 & $+0.2(-0.4-0.8)$ & 0.570 & $+0.3(-2$ to 2$)$ & 0.812 & $+0.3(-0.5$ to 1.2$)$ & 0.449 & $-0.1(-1$ to 1$)$ & 0.865 \\
\hline M 2 & & $+4(0.4-8.5)$ & 0.033 & $-0.2(-0.8$ to 0.4$)$ & 0.503 & $0.2(-0.5-0.9)$ & 0.499 & $+0.4(-2.3$ to 3.2$)$ & 0.754 & $0.3(-0.8$ to 1.4$)$ & 0.617 & $+0.3(-0.7$ to 1.4$)$ & 0.508 \\
\hline $\bar{M} 1$ & \multirow{2}{*}{ Female vs. male } & $-110(-201$ to -18$)$ & 0.019 & $-10(-26$ to 6$)$ & 0.231 & $+7(-19$ to 32$)$ & 0.615 & $-52(-115$ to 12$)$ & 0.110 & $-45(-72$ to -18$)$ & 0.001 & $+44(15-72)$ & 0.002 \\
\hline M 2 & & $-162(-268$ to -55$)$ & 0.003 & $-2(-19$ to 16$)$ & 0.846 & $+4(-18-26)$ & 0.703 & $-51(-128$ to 26$)$ & 0.192 & $-43(-76$ to -11$)$ & 0.009 & $+32(3-61)$ & 0.029 \\
\hline M 1 & \multirow{2}{*}{$\begin{array}{l}\text { History of Myocardial } \\
\text { Infarction }\end{array}$} & $-124(-227$ to -21$)$ & 0.018 & $+5(-15$ to 24$)$ & 0.638 & $-15(-32$ to 3$)$ & 0.095 & $-17(-75$ to 41$)$ & 0.559 & $-24(-46$ to -2$)$ & 0.034 & $+5(-21$ to 31$)$ & 0.696 \\
\hline M 2 & & $-180(-320$ to -40$)$ & 0.011 & $+19(-1$ to 40$)$ & 0.065 & $-27(-47$ to -8$)$ & 0.006 & $-31(-108$ to 47$)$ & 0.437 & $-20(-49$ to 10$)$ & 0.188 & $+0.5(-29$ to 30$)$ & 0.969 \\
\hline M 1 & \multirow{2}{*}{$\begin{array}{l}\text { History of Ventricular } \\
\text { Tachycardia }\end{array}$} & $-61(-156$ to 34$)$ & 0.207 & $-6(-22$ to 9$)$ & 0.432 & $+22(0.8-44)$ & 0.042 & $-57(-122$ to 7$)$ & 0.083 & $-30(-55$ to -4$)$ & 0.022 & $+40(11-69)$ & 0.006 \\
\hline M 2 & & $-70(-165$ to 26$)$ & 0.153 & $-6(-21$ to 9$)$ & 0.426 & $+27(4-46)$ & 0.007 & $-74(-143$ to -5$)$ & 0.034 & $-27(-56$ to 0.8$)$ & 0.057 & $+38(13-63)$ & 0.003 \\
\hline $\mathrm{M} 2$ & Class 3 AA drugs & $+1.2(-74$ to 76$)$ & 0.975 & $+8(-2$ to 18$)$ & 0.137 & $-15(-26$ to -4$)$ & 0.010 & $+19(-105$ to 253$)$ & 0.420 & $-1(-19$ to 18$)$ & 0.950 & $+13(-8$ to 33$)$ & 0.228 \\
\hline
\end{tabular}

Model 1 was adjusted by corresponding QRS variable, age, sex, history of MI, and history of VT. Model 2 was in addition adjusted by LVEF, history of diabetes, hypertension, VT, use of ACEi/ARBs, and class III antiarrhythmic (AA) drugs. Corresponding QRS variable for each model: area QRS azimuth for area T azimuth and area SVG azimuth, area QRS elevation for area T elevation and area SVG elevation, QRS area for T area models. 
Table 4. Demographic and clinical characteristics associated with change in activation (QRS vector) in DDD mode

\begin{tabular}{|c|c|c|c|c|c|}
\hline & \multirow[b]{2}{*}{ Characteristic } & \multicolumn{4}{|c|}{ Outcome variables in DDD mode } \\
\hline & & $\begin{array}{l}\text { Area QRS azimuth } \\
(95 \% \mathrm{CI}){ }^{\circ}\end{array}$ & $\mathrm{P}$ & $\begin{array}{l}\text { QRS area } \\
(95 \% \mathrm{CI}), \mathrm{mV}^{*} \mathrm{~ms}\end{array}$ & $\mathrm{P}$ \\
\hline M 1 & Activation change & $+10(4-15)$ & $<0.0001$ & $+28(17-38)$ & $<0.0001$ \\
\hline M 2 & (Day 1- Day 7) & $+10(5-15)$ & $<0.0001$ & $+24(13-36)$ & $<0.0001$ \\
\hline M 1 & \multirow{2}{*}{$\begin{array}{l}\text { Corresponding } \mathrm{T} \\
\text { variable* }^{*}\end{array}$} & $+0.9(0.7-1.1)$ & $<0.0001$ & $+0.6(0.4-0.8)$ & $<0.0001$ \\
\hline M 2 & & $+0.9(0.7-1.0)$ & $<0.0001$ & $+0.5(0.3-0.7)$ & $<0.0001$ \\
\hline M 1 & \multirow{2}{*}{ Age, per 1 y } & $+0.1(-0.3$ to 0.6$)$ & 0.639 & $+0.3(-0.6$ to 1.3$)$ & 0.523 \\
\hline M 2 & & $0.3(-0.02$ to 0.7$)$ & 0.066 & $+0.8(-0.3$ to 1.8$)$ & 0.142 \\
\hline M 1 & \multirow{2}{*}{ Female vs. male } & $-8(-19$ to 5$)$ & 0.213 & $-30(-60$ to 0.1$)$ & 0.051 \\
\hline M 2 & & $-12(-22$ to-2) & 0.023 & $-40(-69$ to -10$)$ & 0.009 \\
\hline M 1 & \multirow{2}{*}{$\begin{array}{l}\text { History of Myocardial } \\
\text { Infarction }\end{array}$} & $-9(-20$ to 3$)$ & 0.137 & $-20(-45$ to 4$)$ & 0.101 \\
\hline M 2 & & $-17(-28$ to -7$)$ & 0.001 & $-28(-56$ to -28$)$ & 0.050 \\
\hline M 1 & \multirow{2}{*}{$\begin{array}{l}\text { History of Ventricular } \\
\text { Tachycardia }\end{array}$} & $+2(-11$ to 15$)$ & 0.746 & $-13(-43$ to 17$)$ & 0.405 \\
\hline M 2 & & $-3(-12$ to 7$)$ & 0.590 & $-20(-47$ to 6$)$ & 0.136 \\
\hline M2 & Class 3 AA drugs M2 & $+2(-4$ to 8$)$ & 0.593 & $+24(3-45)$ & 0.022 \\
\hline M2 & LVEF, per $1 \%$ & $-0.8(-1.3$ to -0.3$)$ & 0.001 & $-0.5(-1.9$ to 0.9$)$ & 0.495 \\
\hline M2 & Diabetes mellitus & $+12(7-19)$ & $<0.0001$ & $+6.4(-9.4$ to 22.3$)$ & 0.427 \\
\hline
\end{tabular}

Model 1 (M1) was adjusted for corresponding T variable, age, sex, history of MI, and history of VT. Model 2 (M2) was in addition adjusted for LVEF, history of diabetes, hypertension, VT, use of ACEi/ARBs, and class III antiarrhythmic (AA) drugs. Corresponding T variable for each model: area $\mathrm{T}$ azimuth for area QRS azimuth, $\mathrm{T}$ area for QRS area models. 
medRxiv preprint doi: https://doi.org/10.1101/19005181; this version posted November 26, 2019. The copyright holder for this preprint (which was not certified by peer review) is the author/funder, who has granted medRxiv a license to display the preprint in perpetuity.

\section{All rights reserved. No reuse allowed without permission.}

\section{Figure 1:}

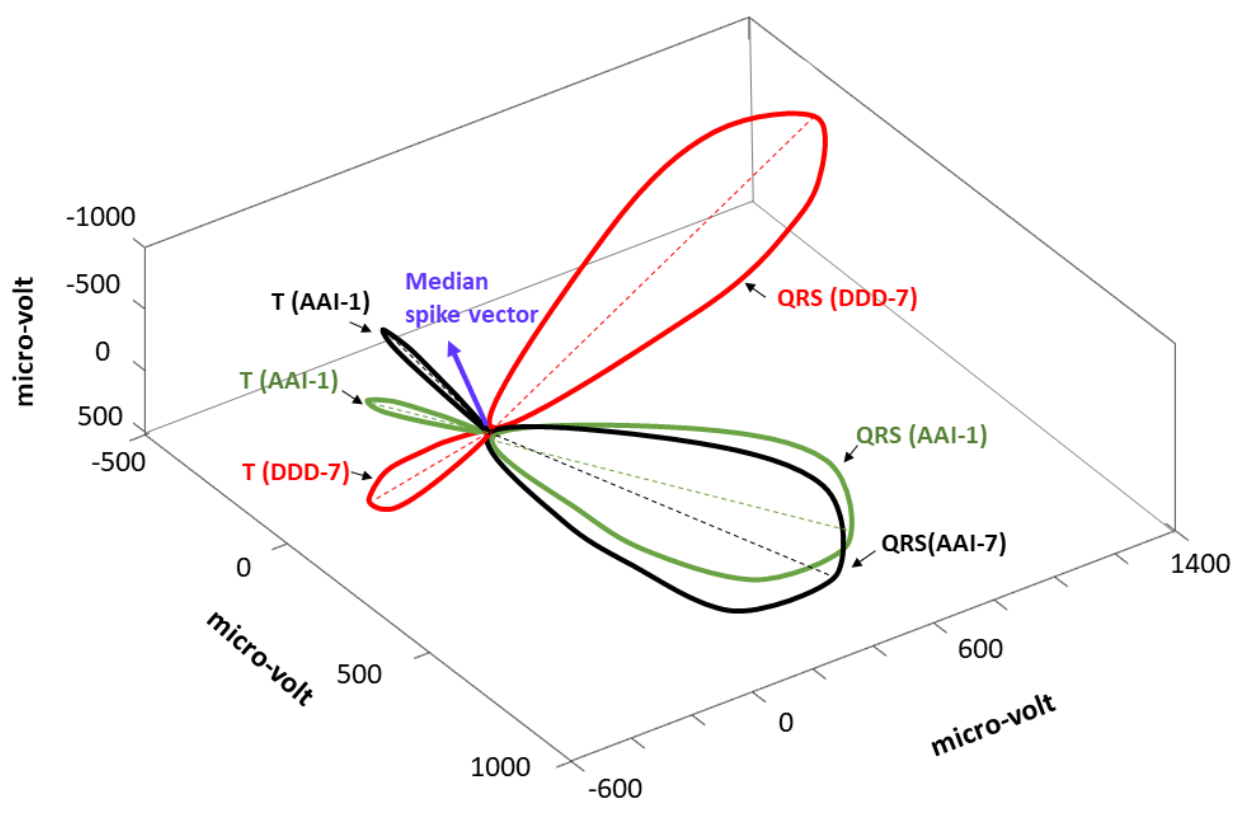




\section{Figure 2:}
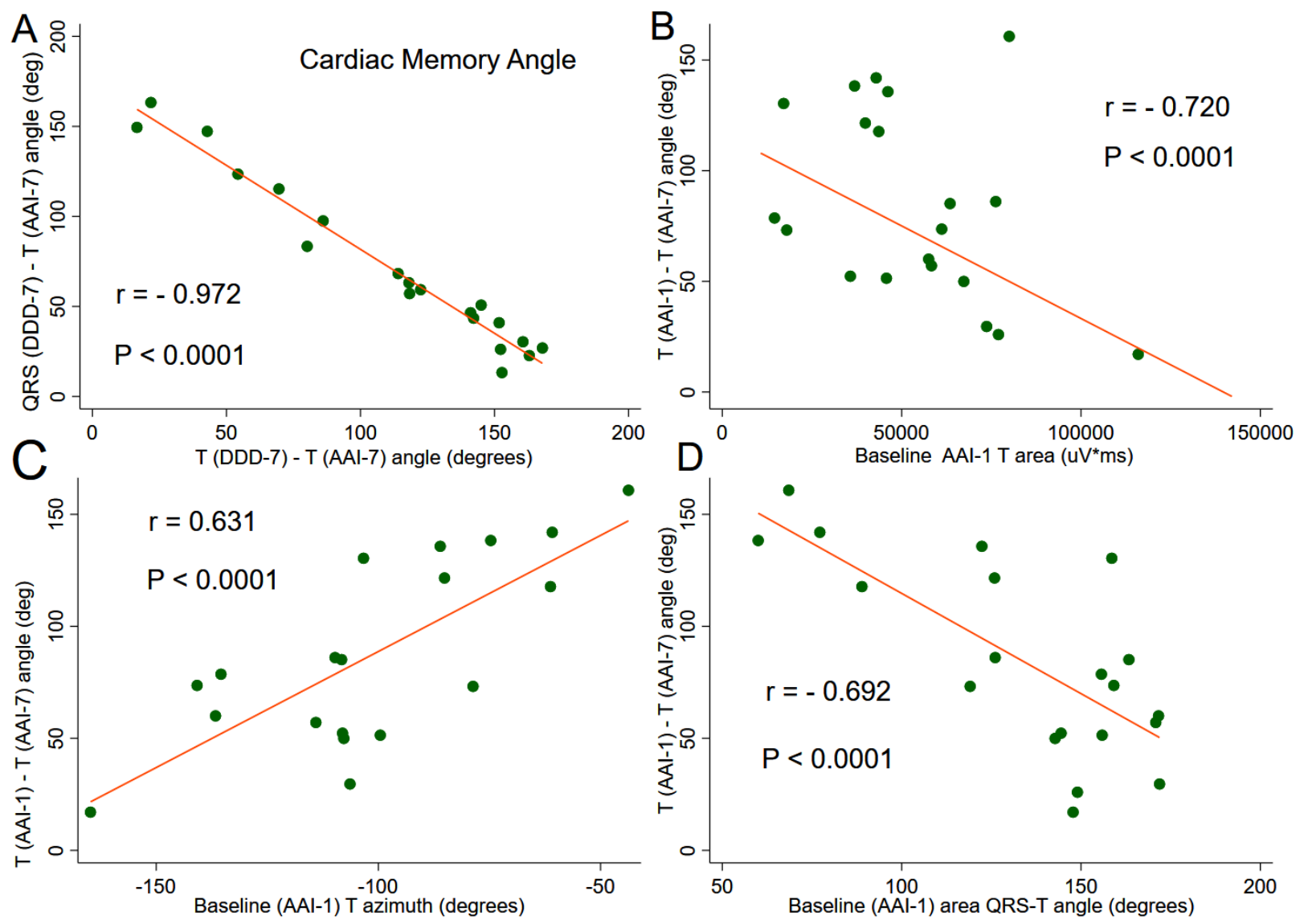


\section{Figure 3:}

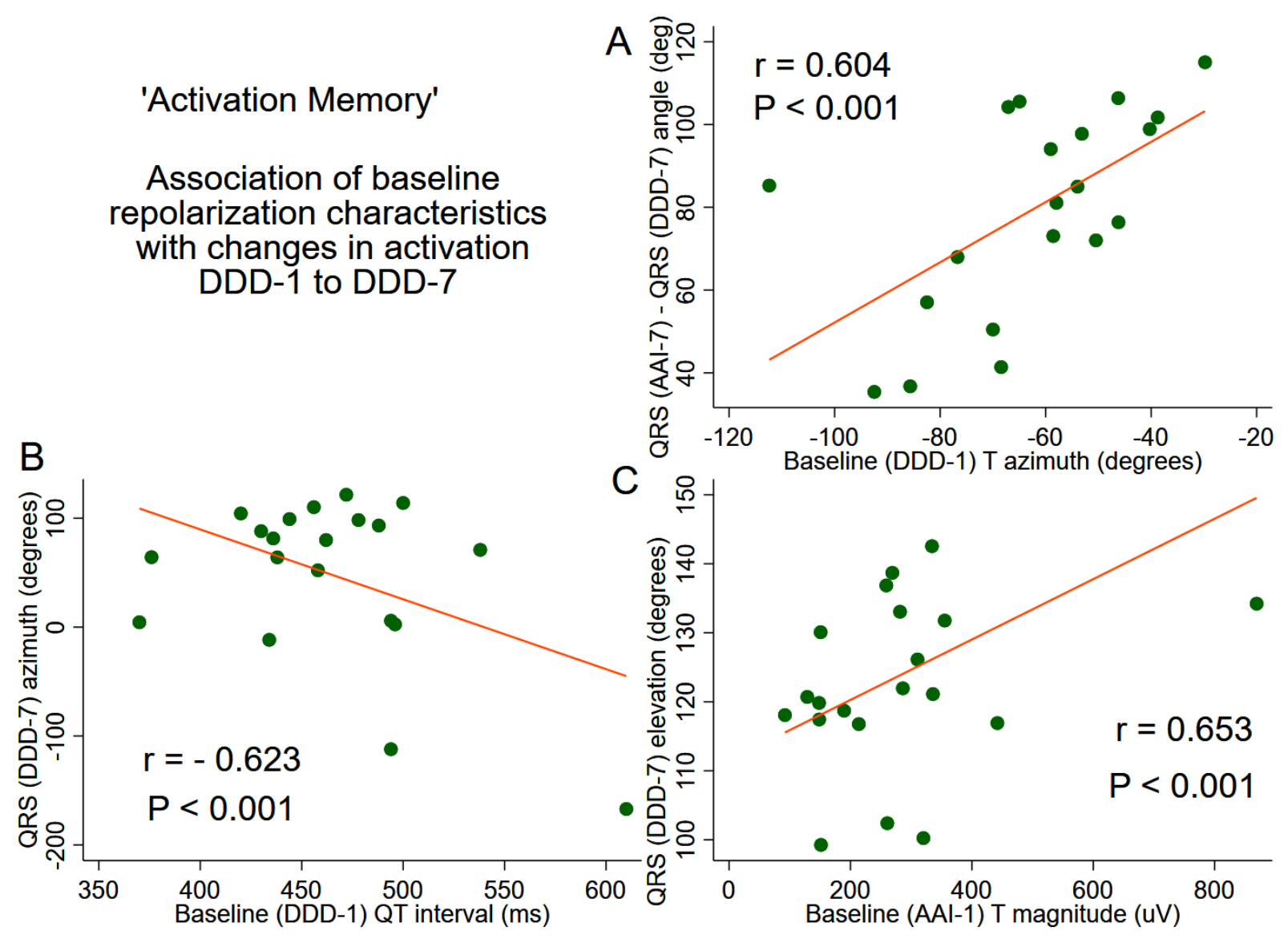




\section{Figure 4:}

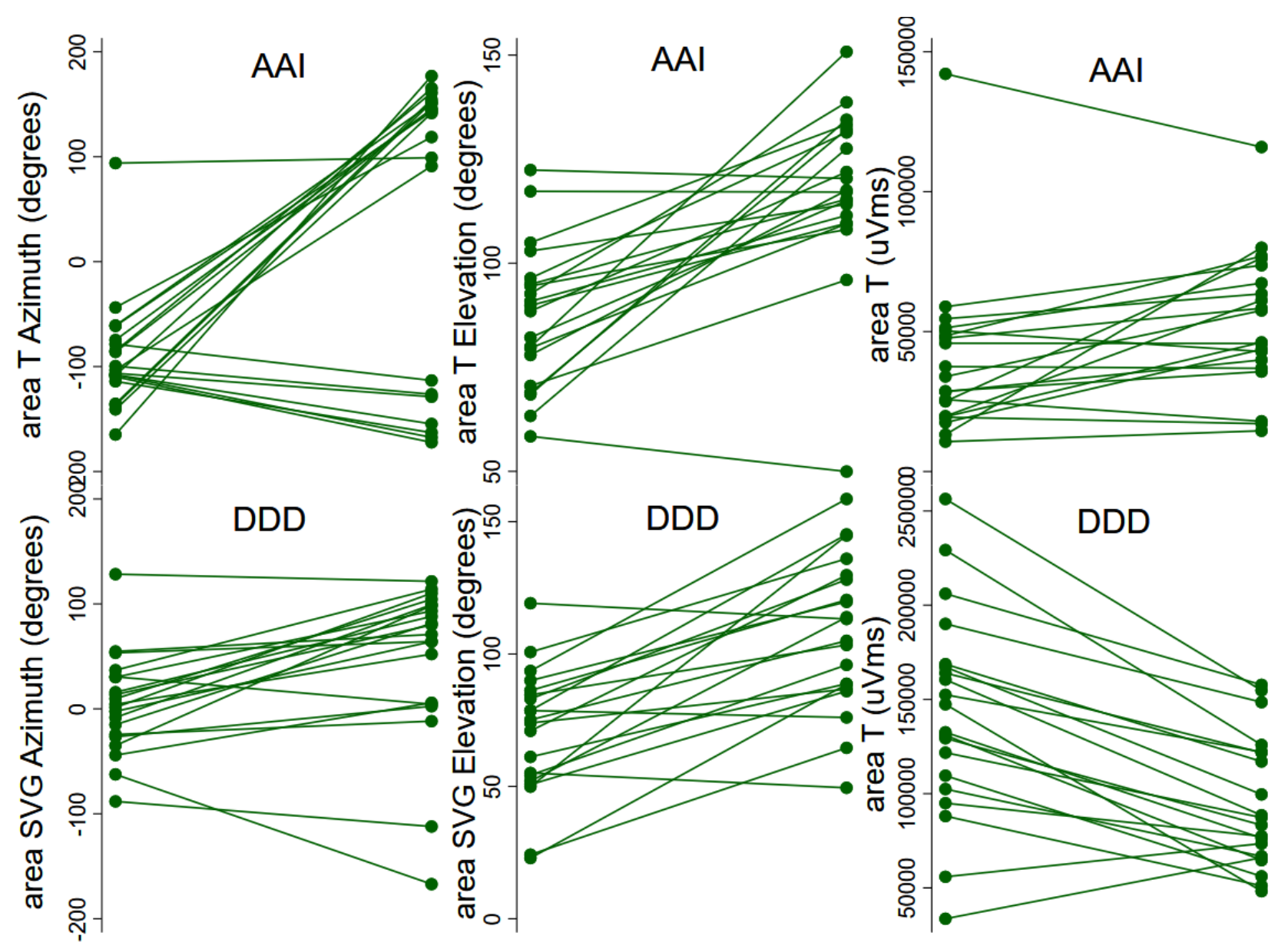




\section{Supplemental Table 1. Peak vectors measurements of cardiac memory development}

\begin{tabular}{|c|c|c|c|c|c|c|c|c|}
\hline ECG and VCG parameters & AAI-1 & DDD-1 & AAI-7 & DDD-7 & $\mathrm{P}_{\text {AAI1-AAI7 }}$ & $\mathrm{P}_{\text {DDD1-DDD7 }}$ & $\mathrm{P}_{\text {AAI1-DDD1 }}$ & $\mathrm{P}_{\text {AAI7-DDD7 }}$ \\
\hline Spatial peak QRS vector magnitude(SD), mV & $1.31(0.41)$ & $1.45(0.43)$ & $1.31(0.35)$ & $1.42(0.40)$ & 0.907 & 0.909 & 0.046 & 0.187 \\
\hline Spatial peak QRS vector azimuth $(95 \% \mathrm{CI}),{ }^{\circ}$ & $32(18-46)$ & $98(89-106)$ & $31(17-44)$ & $102(95-110)$ & 0.964 & 0.326 & $<0.0001$ & $<0.0001$ \\
\hline Spatial peak QRS vector elevation $(95 \% \mathrm{CI}){ }^{\circ}$ & $81(73-88)$ & $121(116-126)$ & $78(71-86)$ & $124(118-130)$ & 0.126 & 0.160 & $<0.0001$ & $<0.0001$ \\
\hline Spatial peak $\mathrm{T}$ vector magnitude(SD), $\mathrm{mV}$ & $0.28(0.17)$ & $0.91(0.29)$ & $0.38(0.14)$ & $0.64(0.17)$ & $\mathbf{0 . 0 0 3}$ & $<0.0001$ & $<0.0001$ & 0.0001 \\
\hline Spatial peak T vector azimuth $(95 \% \mathrm{CI}){ }^{\circ}$ & $-92(-109$ to -74$)$ & $-63(-71$ to -54$)$ & $161(140-182)$ & $-67(-77$ to -58$)$ & $<0.0001$ & 0.168 & $<0.0001$ & $<0.0001$ \\
\hline Spatial peak T vector elevation $(95 \% \mathrm{CI}),{ }^{\circ}$ & $82(73-92)$ & $58(52-63)$ & $119(111-128)$ & $55(50-61)$ & $<0.0001$ & 0.376 & $<0.0001$ & $<0.0001$ \\
\hline Spatial peak SVG vector magnitude(SD), $\mathrm{mV}$ & $0.28(0.17)$ & $0.91(0.29)$ & $0.38(0.14)$ & $0.64(0.17)$ & 0.003 & $<0.0001$ & $<0.0001$ & 0.0001 \\
\hline Spatial peak SVG vector azimuth $(95 \% \mathrm{CI}){ }^{\circ}$ & $27(12-43)$ & $67(52-81)$ & $44(30-57)$ & $91(82-101)$ & 0.001 & 0.003 & $<0.0001$ & $<0.0001$ \\
\hline Spatial peak SVG vector elevation $(95 \% \mathrm{CI}){ }^{\circ}$ & $78(70-85)$ & $112(106-119)$ & $84(78-91)$ & $122(114-130)$ & 0.001 & 0.016 & $<0.0001$ & $<0.0001$ \\
\hline Spatial peak QRS-T angle(95\%CI), ${ }^{\circ}$ & $115(94-135)$ & $161(156-166)$ & $123(114-134)$ & $166(162-169)$ & 0.435 & $\mathbf{0 . 0 2 5}$ & 0.0001 & $<0.0001$ \\
\hline
\end{tabular}

